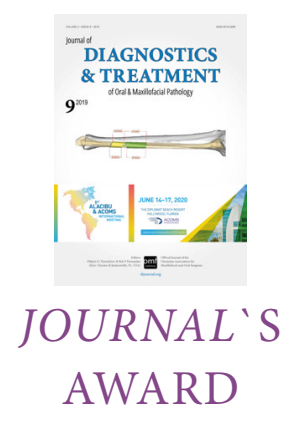

\title{
Journal's Award in 2019: Mark P. Komskyi, ScD, Professor
}

\author{
The first servant-leader in any successful \\ organization is its founder. \\ -Salil Jha \\ Indian-American author
}

Mark P. Komskyi, ScD, Professor (Fig), Corresponding Member of the Ukrainian Academy of Sciences is one of the titans of oral and maxillofacial surgery (OMS) in Eastern Europe and modern Ukraine. The great efforts of Dr. Komskyi are highly recognized by surgical community as for the first time in the history of the institution he organized a completely new structure in City Multiprofile Clinical Hospital \#4, Dnipro, Ukraine: the union of Department of Maxillofacial Surgery and ENT Department in a one City Center for Head and Neck Surgical Pathology, with a capacity of 60 beds on the basis of the Fourth Clinical Medical Association. ${ }^{1}$ In 1992 he was appointed as Chief of that Center, where he is currently working.

His Doctor of Medical Sciences dissertation lifted up the European science of OMS to the new level. The theses were dedicated to highly important chapter of OMS: analysis lymphotropic therapy in complex treatment of patients with osteomyelitis of the mandible. Unstoppable support of Professor Komskyi as Editorial Board member of DTJournal from the year of launching (i.e., 2017) is extremely valuable. ${ }^{2}$

So, it's a greatest honor for the Journal's staff to present honorary plaque to Dr. Komskyi dedicated

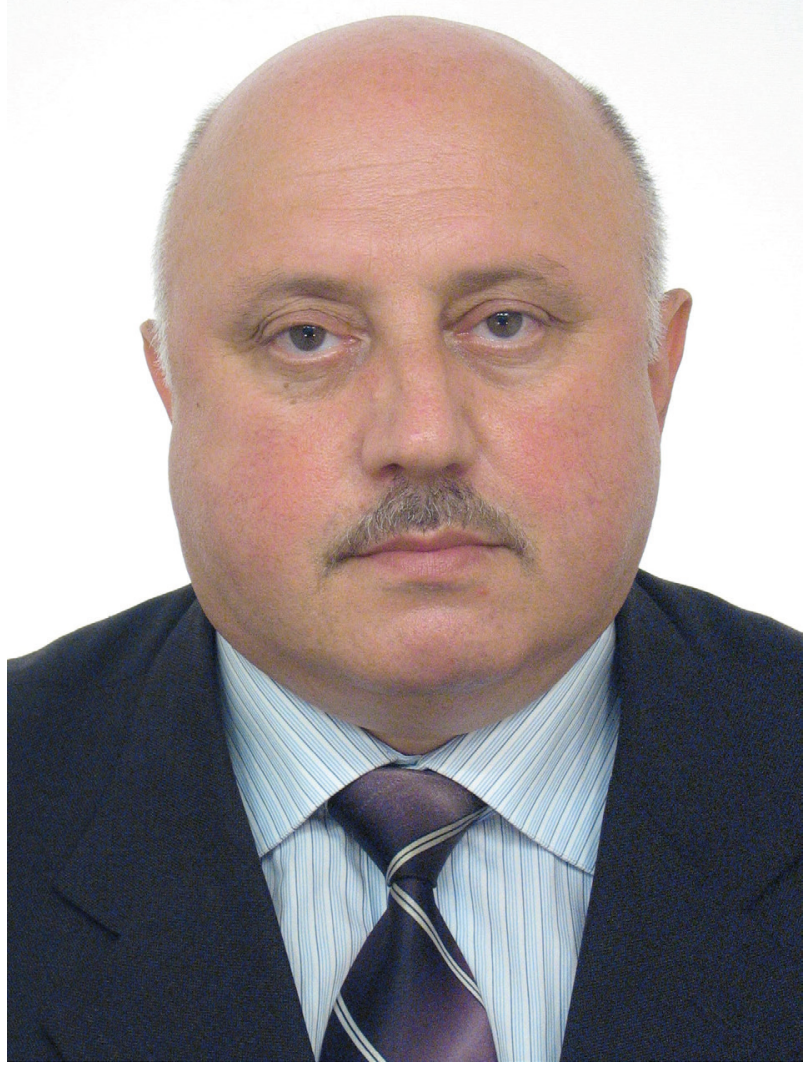

FIGURE. Mark P. Komskyi to a day of his honorary 70th anniversary: "To a 
titan of European and Ukrainian maxillofacial, head and neck surgery for the 44 years of improving of our specialty and for support of the new generations of surgeons sincere thanks and appreciation."

The only way to do great work is to love what you do. -Steve Jobs Co-founder of Apple, Inc

Oleksii O. Tymofieiev, Editor in Chief

Kyiv, Ukraine tymofeev@gmail.com

\section{REFERENCES}

1. City Multiprofile Clinical Hospital \#4 of city Dnipro [document on the internet]; 2019 [cited 2019 Sep 20]. Available from: http://medlib.dp.gov.ua/jirbis2/ ua/lpz-anniversaries/474-miskij-bagatoprofilnijklinichnij-likarni-4-m-dnipropetrovska-25-rokiv. html.

2. Komskyi MP, Romanenko OH, Buzoveria OA, Makohon MV. The integral indicator of the evaluation of the general state severity in patients with inflammatory processes of the mandibular bone according to the data of peripheral clinical blood analysis. J Diagn Treat Oral Maxillofac Pathol 2017;1:168-174. http://dx.doi. org/10.23999/j.dtomp.2017.3-4.10. 